\title{
Resultados da troca de lente intra-ocular de hidrogel opacificada
}

\author{
Outcom es of opacified hydrogel intraocular len sexchange
}

Cristina Mor eir a Saler $a^{1}$

Raissa A guiar Mir an da²

Pedro Paulo Leite dos Reis ${ }^{3}$

Márcia R eis Guimarães ${ }^{4}$

Ricardo Bicalho Campolina ${ }^{5}$

Queiroz Guimarães ${ }^{6}$

\section{RESUMO}

Objetivos: Avaliar os resultados da explantação e substituição das lentes intra-oculares (LIO) de hidrogel opacificadas. Métodos: Foram analisados retrospectivamente os prontuários de 12 pacientes ( 15 olhos) submetidos à explantação e substituição das lentes intra-oculares de hidrogel opacificadas. Resultados: A opacificação das lentes intra-oculares de hidrogel causou perdas de linhas de visão em 13 olhos (86,7\%). A troca das lentes intra-oculares opacificadas promoveu o ganho de linhas de visão em 11 olhos (73,3\%). As complicações peroperatórias ocorreram em três olhos (20\%) e foram as seguintes: perda de óleo de silicone, ruptura total de zônula com perda do saco capsular e ruptura parcial de zônula. Durante a explantação das lentes intra-oculares foi necessária a realização de incisões relaxantes na borda da capsulorrexe anterior em três olhos (20\%) e em dois olhos $(13,3 \%)$ os hápticos foram cortados sendo retirada somente a zona óptica das lentes intra-oculares. Conclusão: A cirurgia para explantação e substituição das lentes intra-oculares opacificadas mostrou-se eficaz naqueles pacientes com perdas de linhas de visão $(\mathrm{p}>0,05)$.

Descritores: Remoção de dispositivo; Implante de lente intra-ocular; Lentes intraoculares; Reoperação; Hidrogel; Facoemulsificação; Acuidade visual

\section{INTR ODUÇÃ O}

Com o advento da facoemulsificação e das cirurgias de catarata com pequenas incisões temos observado o constante desenvolvimento de diversos tipos de lentes intra-oculares dobráveis ${ }^{(1-2)}$. O hidrogel, um biomaterial amplamente utilizado na medicina há vários anos e recentemente utilizado na confecção de lentes intra-oculares (LIO), é um material acrílico hidrofílico com diferentes composições químicas e uma porcentagem de água que pode variar de $18 \%$ a $30 \%{ }^{(1)}$.

Apesar da sua biocompatibilidade e da sua baixa adesividade tem sido observada a ocorrência de uma opacificação tardia destas lentes ${ }^{(2-7)}$ causadas por precipitados de cálcio $^{(6)}$, que tem causado piora da acuidade visual $^{(3-8)}$ (Foto 1). Vários fatores têm sido avaliados com o objetivo de se determinar a causa deste fenômeno, são eles: a embalagem da LIO, soluções intra-oculares, viscoelásticos, técnica cirúrgica e patologias sistêmicas e oculares associadas $^{(2-4,7-8)}$. Mesmo ainda não tendo sido liberadas pelo "FDA" (Food and Drug Administration), as lentes intra-oculares de hidrogel são comercializadas fora dos Estados Unidos ${ }^{(8)}$.

As lentes usadas neste estudo, de acordo com informações do fabricante, apresentaram opacificação da superfície da lente devido a uma calcificação de minerais encontrados no anel de silicone de vedação da tampa da embalagem. 


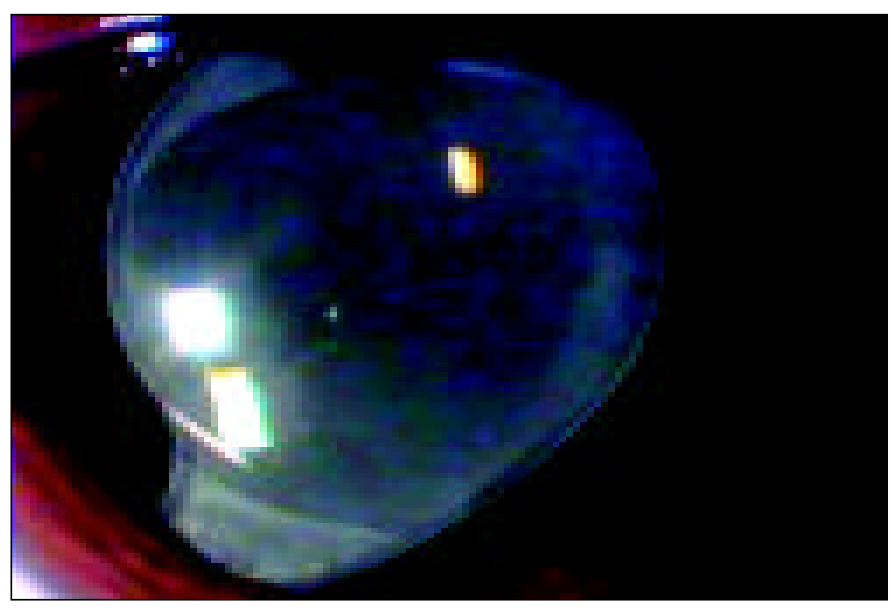

Foto 1 - Lente intra-ocular de hidrogel opacificada

Inicialmente, tentou-se a remoção do depósito sobre a lente com Nd: $\mathrm{Yag}^{(5)}$, entretanto, este tratamento mostrou-se incapaz de remover o depósito ou de melhorar a visão. A outra opção para tratar estes casos foi a realização da troca da lente opacificada que, por sua vez, tem mostrado melhora na acuidade visual ${ }^{(5)}$. No presente estudo os pacientes foram submetidos à explantação e substituição da lente. A técnica cirúrgica, as dificuldades, as complicações e os resultados foram analisados.

\section{MÉTODOS}

\section{Pacientes}

Foram avaliados, retrospectivamente, os prontuários de 12 pacientes (15 olhos) que foram submetidos à facoemulsificação com implante de LIO dobrável de hidrogel, seguido de opacificação das lentes intra-oculares e realização da troca da lente.

As cirurgias de facoemulsificação foram realizadas no período de junho de 2000 a junho de 2001 e as cirurgias de troca da LIO foram realizadas no período de dezembro de 2001 a agosto de 2002.

A avaliação pré-operatória para as duas cirurgias incluiu o seguinte:

- anamnese (idade, sexo, doenças oculares, doenças sistêmicas);

- refração;

- medida da pressão intra-ocular;

- biomicroscopia;

- fundoscopia;

- microscopia especular (microscópio especular computadorizado sem contato);

- ecobiometria (ecógrafo A com sonda de contato);

- "PAM" (Potential Acuity Meter).

A rotina para preparação do paciente consistiu em sedação com midazolan (Dormonid ${ }^{\circledR}$ ) $3 \mathrm{ml}$ intravenoso e cloridrato de fentanil 0,5 mg (Fentanil $\left.{ }^{\circledR}\right) 1 \mathrm{ml}$ intravenoso. Para dilatação da pupila utilizou-se uma gota dos seguintes colírios: cloridrato de proximetacaína (Anestalcon ${ }^{\circledR}$ ), tropicamida (Mydriacyl $^{\circledR}$ ), cloridrato de fenilefrina (Fenilefrina ${ }^{\circledR}$ ) e flurbiprofeno (Ocufen ${ }^{\circledR}$ ). Em todos os pacientes as cirurgias foram realizadas com bloqueio peribulbar utilizando-se $6 \mathrm{ml}$ de cloridrato de lidocaína 2\% com vasoconstritor (1:400.000).

Quanto à técnica cirúrgica da facoemulsificação, inicialmente duas incisões auxiliares "side-port" eram realizadas afastadas $180^{\circ}$ uma da outra e a $90^{\circ}$ da incisão principal que era realizada no lado temporal ou no meridiano mais curvo da córnea com o objetivo de reduzir o astigmatismo corneano pré-operatório. A seguir a capsulorrexis era realizada com cistítimo sob irrigação controlada seguida pela incisão principal "clear cornea" cuja extensão padrão era 3,0 mm podendo ser estendida para 3,2 a 3,5 mm quando se objetivava o aplanamento corneano. Posteriormente realizava-se a hidrodissecção e a facoemulsificação. A aspiração do córtex residual e o polimento da cápsula posterior eram realizados manualmente e utilizava um mantenedor de câmara anterior com irrigação contínua de BSS. Após a injeção de viscoelástico a incisão era ampliada e a LIO de hidrogel era inserida no saco capsular com o auxílio de pinça. Então, o resíduo de viscoelástico era removido através do sistema de irrigação e aspiração automatizada. Para finalizar, a câmara anterior era preenchida com solução salina e, se necessário, era realizada hidratação do estroma corneano adjacente às incisões ou sutura com mononylon 10-0.

Para a cirurgia de explantação da LIO opacificada também eram realizadas, inicialmente, duas incisões auxiliares "sideport" às 12 e às 6 horas e a câmara anterior era preenchida com viscoelástico de alto peso molecular para proteção endotelial e manutenção da câmara anterior. Era, então, iniciada a mobilização da LIO com os ganchos de Sinskey e Y. Os ganchos eram utilizados para liberar a lente do saco capsular, dissecando-a das cápsulas anterior e posterior, procurando luxar a parte óptica da LIO para a câmara anterior. A seguir tentava-se uma rotação da LIO para liberação das alças. Após o posicionamento da LIO na câmara anterior, a incisão principal era realizada com 3,5 a 5,0 mm de extensão e a lente era removida. Caso existisse dificuldade em manipular e/ou posicionar a lente na câmara anterior em função do pequeno diâmetro da capsulorrexis, duas incisões relaxantes eram realizadas com tesoura de Vannas nas bordas da capsulorrexis anterior. Se, durante a tentativa de mobilização da LIO, notava-se a presença de aderência dos hápticos com a cápsula estes eram cortados e deixados no saco capsular, sendo removida somente a parte óptica da lente opacificada. Após a remoção parcial ou total da lente dava-se início ao processo de aspiração manual daqueles casos em que eram observadas a presença de proliferação celular sobre a cápsula posterior. Finalmente, a nova lente intra-ocular de PMMA era colocada no saco capsular ou no sulco e três suturas eram realizadas com mononylon 10-0. Em um caso em que houve ruptura das zônulas e remoção da lente opacificada juntamente com o saco capsular, foi realizada fixação escleral da LIO. 
O valor dióptrico da LIO de PMMA foi calculado com o objetivo de deixar os pacientes emétropes.

O paciente era examinado no dia seguinte e após 30 dias de cirurgia, além disso, os pacientes eram orientados a nos comunicar qualquer intercorrência. No período pós-operatório foi prescrito para uso tópico a associação antibiótico/corticóide (sulfato de neomicina/sulfato de polimixina B e dexametasona) inicialmente quatro vezes ao dia com redução de uma gota a cada semana durante um mês.

\section{Análise estatística}

Para a análise estatística optou-se pela realização do teste não paramétrico de Wilcoxon para amostras pareadas (Wilcoxon signed-Rank Test), uma vez que se tratam de comparações do tipo pré e pós. Os testes não paramétricos são indicados quando a amostra é pequena e apresenta dados discrepantes. Nestes casos, os resultados da análise estatística devem ser compreendidos não como suporte para se realizar inferências e sim como indicativo de tendências, para serem confirmadas em outro estudo de maior porte sobre o tema. As diferenças foram consideradas significativas para $\mathrm{p}<0,05$.

\section{RESULTADOS}

O grupo estudado era composto por 15 olhos de 12 pacientes sendo que quatro $(33,3 \%)$ eram do sexo feminino e oito $(66,7 \%)$ do sexo masculino. Destes pacientes, em três (25\%) a explantação da lente foi realizada em ambos os olhos. A idade no momento da cirurgia de facoemulsificação variou de 53 a 79 anos com média igual a 66,25 anos. Na época da realização da explantação da LIO a média de idade era 67,8 anos (variando de 55 a 81 anos).

O intervalo de tempo médio entre a cirurgia de facoemulsificação e a percepção de piora da visão pelo paciente foi de 16,4 meses (variando de 6 a 23 meses) e o intervalo de tempo médio entre o implante e a explantação da lente opacificada foi de 18,5 meses (variando de 10 a 25 meses).
Em sete olhos (46,6\%) não existia doença sistêmica associada. Em três olhos (20\%) havia associação com hipertensão arterial sistêmica, em quatro $(26,7 \%)$ com diabetes melitus e em um $(6,7 \%)$ com polimiosite.

Quanto à presença de doenças oculares associadas, em três olhos (20\%) foi encontrada degeneração macular relacionada à idade forma seca. Em um olho $(6,7 \%)$ a cirurgia de facoemulsificação foi realizada após vitrectomia e retinopexia e, também em um olho $(6,7 \%)$ a cirurgia de catarata foi realizada após vitrectomia e membranectomia. Dois olhos (13,3\%) apresentavam retinopatia diabética, um olho $(6,7 \%)$ apresentava glaucoma primário de ângulo aberto e um olho $(6,7 \%)$ apresentava retinopatia diabética e glaucoma neovascular.

No que diz respeito à técnica utilizada para a explantação da LIO, em três olhos (20\%) foi necessária a realização de duas incisões relaxantes na borda da capsulorrexis anterior, em dois olhos $(13,3 \%)$ a LIO opacificada teve os seus hápticos cortados e somente a sua zona óptica foi removida e em 10 olhos $(66,7 \%)$ a explantação foi realizada somente através da mobilização da lente.

A LIO de PMMA foi implantada no sulco em 11 olhos $(73,3 \%)$, no saco capsular em três olhos $(20 \%)$ e em um olho $(6,7 \%)$ foi necessária a realização de fixação escleral.

As complicações durante a cirurgia para explantação da lente foram as seguintes: perda de óleo de silicone (um olho$6,7 \%$ ), ruptura de zônula com remoção do saco capsular (um olho-6,7\%) e ruptura localizada de zônula (um olho-6,7\%). Em 12 olhos (80\%) não ocorreram complicações per-operatórias. A tabela 1 mostra os dados dos pacientes.

Quanto às complicações pós-operatórias, foram encontradas as seguintes: opacificação de cápsula posterior (quatro olhos-26,6\%), Seidel espontâneo pela incisão principal (um olho-6,7\%), edema macular cistóide (um olho-6,7\%) e em oito olhos $(53,3 \%)$ não foram observadas complicações como mostra a tabela 2 .

Quando comparamos a acuidade visual com correção antes e após a opacificação da lente observamos a ocorrência de piora da mesma. Três olhos (20\%) perderam uma linha de visão, seis

\begin{tabular}{|c|c|c|c|c|c|c|c|c|c|c|c|c|c|c|c|}
\hline \multicolumn{16}{|c|}{ Tabela 1. Dados dos pacientes } \\
\hline Iniciais & Sexo & Idade & Olho & $\begin{array}{l}\text { Data } \\
\text { faco }\end{array}$ & $\begin{array}{c}\text { AVCC } \\
\text { sem } \\
\text { opacificação }\end{array}$ & $\begin{array}{c}\text { AVCC } \\
\text { com } \\
\text { opacificação }\end{array}$ & $\begin{array}{c}\text { Diagnóstico } \\
\text { opacificação } \\
\text { (meses) }\end{array}$ & $\begin{array}{l}\text { Data } \\
\text { troca }\end{array}$ & $\begin{array}{l}\text { AVCC } \\
\text { após a } \\
\text { troca }\end{array}$ & $\begin{array}{l}\text { Corte da } \\
\text { zona } \\
\text { óptica }\end{array}$ & $\begin{array}{l}\text { Incisões } \\
\text { relaxantes }\end{array}$ & $\begin{array}{c}\text { Complicações } \\
\text { per-operatórias }\end{array}$ & $\begin{array}{l}\text { Posição } \\
\text { da LIO }\end{array}$ & $\begin{array}{l}\text { Doença } \\
\text { ocular }\end{array}$ & $\begin{array}{l}\text { Doença } \\
\text { sistêmica }\end{array}$ \\
\hline TO & $\mathrm{F}$ & 54 & D & $15 / 02 / 01$ & vultos & vultos & 7 & $03 / 01 / 02$ & vultos & nāo & nāo & $\begin{array}{l}\text { perda de óleo } \\
\text { de silicone }\end{array}$ & sulco & $\begin{array}{l}\text { pós-vitrectomia } \\
\text { e retinopexia }\end{array}$ & - \\
\hline DLS & $\mathrm{F}$ & 59 & D & 29/06/02 & $20 / 20$ & $20 / 30$ & 20 & $10 / 04 / 02$ & $20 / 20$ & $\operatorname{sim}$ & não & - & sulco & - & polimiosite \\
\hline JMS & M & 76 & D & $15 / 06 / 00$ & $20 / 20$ & $20 / 50$ & 17 & $20 / 12 / 01$ & $20 / 25$ & não & não & - & sulco & DMRI seca & HAS \\
\hline JAT & M & 72 & D & $21 / 09 / 00$ & $20 / 25$ & $20 / 40$ & 13 & $06 / 12 / 01$ & $20 / 20$ & nāo & não & - & saco & - & HAS \\
\hline JPF & M & 79 & D & 27/06/00 & $20 / 25$ & $20 / 50$ & 20 & $31 / 01 / 02$ & $20 / 25$ & não & sim & - & sulco & DMRI seca & - \\
\hline JPF & M & 79 & E & $29 / 06 / 00$ & $20 / 25$ & $20 / 70$ & 20 & $07 / 03 / 02$ & $20 / 30$ & não & sim & - & sulco & DMRI seca & - \\
\hline WP & M & 75 & D & 26/06/00 & 20/20 & $20 / 30$ & 20 & 05/03/02 & $20 / 20$ & não & não & - & sulco & - & - \\
\hline WP & M & 75 & E & $21 / 06 / 00$ & $20 / 20$ & $20 / 30$ & 20 & 19/03/02 & $20 / 25$ & não & não & $\begin{array}{l}\text { ruptura total } \\
\text { de zônula }\end{array}$ & $\mathrm{FE}$ & - & - \\
\hline JGS & M & 54 & E & $26 / 04 / 01$ & $20 / 40$ & $20 / 60$ & 14 & 19/02/02 & vultos & não & não & - & saco & RD, GN & DM \\
\hline ED & M & 66 & D & 20/03/01 & $20 / 20$ & $20 / 25$ & 14 & $27 / 06 / 02$ & $20 / 25$ & não & não & - & sulco & G & DM \\
\hline TMGC & M & 67 & D & 05/04/01 & $20 / 30$ & $20 / 50$ & 8 & 26/02/02 & $20 / 30$ & não & não & - & saco & RD & DM \\
\hline TMGC & M & 67 & E & $26 / 06 / 01$ & $20 / 30$ & $20 / 40$ & 6 & $28 / 05 / 02$ & $20 / 30$ & não & não & - & sulco & $\mathrm{RD}$ & DM \\
\hline RNA & $\mathrm{F}$ & 76 & E & $27 / 06 / 00$ & 20/20 & $20 / 20$ & 21 & $30 / 07 / 02$ & $20 / 20$ & não & não & - & sulco & - & HAS \\
\hline MLS & $\mathrm{F}$ & 64 & E & $22 / 08 / 00$ & $20 / 25$ & $20 / 200$ & 23 & $02 / 07 / 02$ & $20 / 25$ & sim & não & $\begin{array}{l}\text { ruptura parcial } \\
\text { de zônula }\end{array}$ & sulco & $\begin{array}{l}\text { pós-vitrectomia e } \\
\text { membranectomia }\end{array}$ & - \\
\hline CJO & M & 53 & D & $18 / 09 / 00$ & 20/25 & $20 / 30$ & 23 & 06/08/02 & $20 / 20$ & não & sim & - & sulco & - & - \\
\hline
\end{tabular}




\begin{tabular}{|lc|}
\hline \multicolumn{2}{|c|}{ Tabela 2. Complicações pós-operatórias } \\
Complicações pós-operatórias & Número de olhos (\%) \\
Opacificação de cápsula posterior & $4(26,6 \%)$ \\
Seidel pela incisão principal & $1(6,7 \%)$ \\
Edema macular cistóide & $1(6,7 \%)$ \\
Sem complicações pós-operatórias & $8(53,3 \%)$ \\
\hline
\end{tabular}

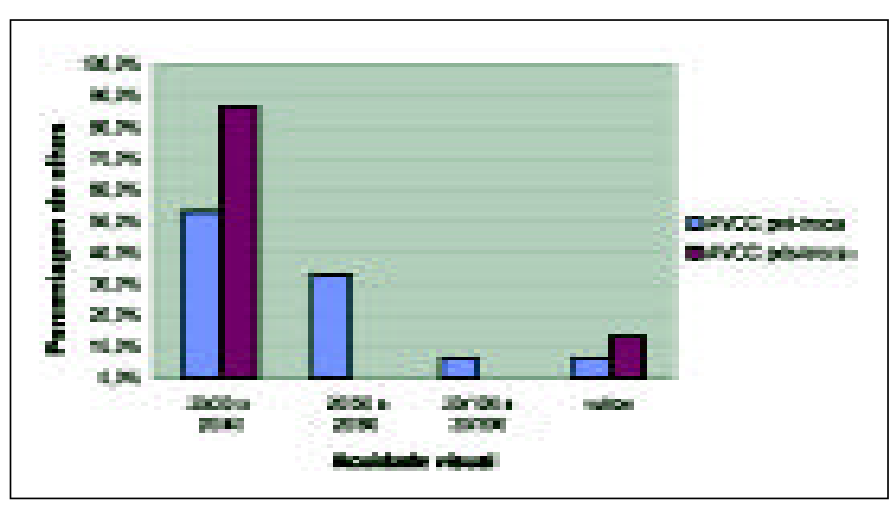

Grafico 1 - AVCC antes e após a troca da LIO opacificada

(40\%) perderam duas linhas de visão, um $(6,7 \%)$ perdeu três linhas de visão, três (20\%) perderam mais de três linhas de visão e dois $(13,3 \%)$ mantiveram a mesma acuidade visual. A acuidade visual com correção mediana (medida que melhor se aproxima matematicamente do teste não-paramétrico) antes da ocorrência da opacificação era 20/25 e após a opacificação era 20/40. Comparando-se esta distribuição, o teste não mostrou diferença estatisticamente significativa $(p=0,07$, Teste de Wilcoxon para amostras pareadas).

Após a explantação da LIO opacificada e implantação de uma lente de PMMA observamos a perda de linhas de visão em um olho $(6,7 \%)$, três olhos (20\%) mantiveram a mesma acuidade visual, dois olhos $(13,3 \%)$ ganharam uma linha de visão, quatro olhos $(26,7 \%)$ ganharam duas linhas de visão, três olhos (20\%) ganharam três linhas de visão e dois olhos $(13,3 \%)$ ganharam mais de três linhas de visão. O gráfico 1 mostra a distribuição da AVCC antes e após a troca da LIO. A análise das medianas referentes à AVCC com opacificação (20/40) e AVCC após a troca da LIO (20/25) também não mostrou diferença estatisticamente significativa $(p>0,05)$.

Ao compararmos a acuidade visual com correção após a troca e a acuidade visual antes da ocorrência de opacificação da lente observamos que em $53,3 \%$ dos olhos ( 8 olhos) a acuidade visual foi mantida, em quatro olhos $(26,7 \%)$ ocorreu perda de uma linha de visão, em um olho $(6,7 \%)$ ocorreu perda de mais de três linhas de visão, em dois olhos $(13,3 \%)$ houve ganho de uma linha de visão. A análise das medianas referentes à AVCC sem opacificação (20/25) e AVCC após a substituição da LIO (20/25) também não indicou diferença estatisticamente significativa $(p>0,05)$.
Quanto à refração dos pacientes antes e após a explantação e substituição da lente o equivalente esférico médio préoperatório era $-0,88$ dioptrias e o pós-operatório era $-0,43$ dioptrias.

Os dois olhos em que foi necessária a secção da zona óptica da LIO e cujas alças permaneceram no saco capsular também mantiveram a mesma acuidade visual com correção de antes da ocorrência de opacificação da lente.

Dos pacientes que tiveram complicações per-operatórias, um olho no qual ocorreu perda de óleo de silicone manteve a mesma acuidade visual com correção. Em um olho que apresentou ruptura localizada de zônula, a acuidade visual com correção também foi mantida. No olho em que ocorreu ruptura de zônula com perda do saco capsular notou-se perda de uma linha de visão na acuidade visual corrigida.

\section{DISCUSSÃ O}

A ocorrência de opacificação das lentes intra-oculares de hidrogel foi relatada pela primeira vez em $1987^{(9)}$. Esta opacificação é um fenômeno multifatorial que envolve as características do material e o seu meio de conservação ${ }^{(2,9)}$, e, recentemente, vem sendo uma importante indicação para explantação e substituição da lente opacificada ${ }^{(5,8)}$.

No presente estudo, o tempo decorrido entre o implante da lente e a percepção de piora da visão pelo paciente variou de 6 a 23 meses (média de 16,4 meses). Na literatura encontramos período de tempo semelhante que variou de 4 a 26 meses $^{(3)}$.

A presença de doença sistêmica associada foi observada em oito olhos $(53,4 \%)$. Entretanto, a relação entre estas doenças e o risco de opacificação das lentes intra-oculares ainda necessita de maiores estudos. Em recente análise, não foi estabelecida relação entre o diabetes e esta complicação ${ }^{(4)}$.

É interessante ressaltar que, durante a cirurgia de explantação da LIO, pode-se encontrar uma intensa aderência dos hápticos com o saco capsular. Nestes casos, para que não haja maiores complicações, como ruptura de zônula, faz-se necessário o corte dos hápticos, removendo-se somente a zona óptica da LIO opacificada que, como foi observado, não se adere ao saco capsular ${ }^{(5)}$.

Optou-se por implantar uma nova lente de PMMA devido à sua superior biocompatibilidade, à grande probabilidade desta lente ser implantada no sulco e porque a incisão cirúrgica já era ampliada para a remoção da LIO opacificada. A maioria das LIOs $(73,3 \%)$ foi implantada no sulco. Este fato se deve ao relaxamento excessivo do saco capsular após a retirada da LIO e também à presença de aderências entre a cápsula posterior e anterior dificultando o posicionamento ideal da nova LIO no saco capsular.

A opacificação das LIOs de hidrogel levou à perda de linhas de visão em 13 olhos (86,7\%). Em dois olhos (13,3\%) a explantação e troca da lente foi indicada devido às queixas de má qualidade visual. 
A troca da LIO opacificada proporcionou uma melhora da acuidade visual corrigida (AVCC) em nove olhos $(73,3 \%)$ e manteve a mesma AVCC em três (20\%). Resultados semelhantes foram descritos na literatura ${ }^{(5)}$. Em um olho (caso 9) ocorreu importante perda de linhas de visão em função da descompensação da retinopatia diabética proliferativa e do glaucoma neovascular após a cirurgia de troca da lente.

Nota-se, também, que após a explantação e substituição da LIO houve perda de linhas de visão em cinco olhos $(33,4 \%)$ comparando-se com a AVCC antes da opacificação da lente. Ao compararmos com a AVCC com a lente opacificada, somente um olho $(6,7 \%)$ perdeu linhas de visão. Este dado também foi observado em outro estudo, entretanto, a diferença não foi estatisticamente significativa ${ }^{(5)}$.

O fato de ocorrer melhora da visão com a substituição da LIO sugere que o processo de opacificação da lente seja um fenômeno localizado e que não produz danos às outras estruturas oculares ${ }^{(5)}$.

Portanto, a explantação e substituição da LIO intra-ocular mostrou-se efetiva naqueles pacientes com baixa acuidade visual em função da opacificação. Após a troca da lente grande parte dos pacientes recupera a mesma visão de antes da opacificação da lente.

\section{CONCLUSÕES}

A opacificação das lentes intra-oculares de hidrogel foi diagnosticada, em média, 16,4 meses após a sua implantação e foi responsável por perda de linhas de visão ou piora na qualidade visual. Quanto à cirurgia para explantação da lente, uma meticulosa dissecção entre a LIO e o saco capsular deve ser realizada e caso ainda ocorra áreas de aderência, pode-se tentar facilitar a liberação da LIO através da realização de incisões na borda da capsulorrexis ou seccionando os hápticos e removendo somente a zona óptica da lente. A troca da LIO proporcionou a recuperação da acuidade visual em grande parte dos pacientes. Entretanto, apesar dos resultados satisfatórios, estudos envolvendo um maior número de casos são necessários.

\section{ABSTRACT}

Purpose: To evaluate the outcomes of intraocular lens (IOL) exchange in eyes with opacified hydrogel IOLs. Methods: We analyzed retrospectively the charts of 12 patients (15 eyes) who had been submitted to opacified intraocular lens exchange. Results: The opacified hydrogel intraocular lens caused decreased visual acuity in 13 eyes $(86,7 \%)$. The opacified intraocular lens exchange improved visual acuity in 11 eyes $(73,3 \%)$. Three eyes $(20 \%)$ had the following complications during surgery: silicone oil loss, complete zonular dehiscence with loss of capsular bag and partial zonular dehiscence. During the intraocular lens exchange it was necessary to perform relaxing incisions in the anterior capsulorrhexis edge in three eyes $(20 \%)$ and, in two eyes $(13,3 \%)$ it was necessary to cut the haptics removing only the optical zone of the intraocular lens. Conclusion: Intraocular lens exchange was an effective treatment in patients with opacified hydrogel intraocular lens $(\mathrm{p}>0,05)$.

Keywords: Device removal; Lens implantation, intraocular; Lenses intraocular; Reoperation; Hydrogel; Phacoemulsification; Visual acuity

\section{REFERENCIAS}

1. Tognetto D, Toto L, Ballone E, Ravalico G. Biocompatibility of hydrophilic intraocular lenses. J Cataract Refract Surg 2002;28:644-51.

2. Frohn A, Dick HB, Augustin AJ, Grus FH. Late opacification of the foldable hydrophilic acrylic lns SC60B-OUV. Ophthalmology 2001;108:1999-2004.

3. Yu AK, Kwan KY, Chan DH, Fong DY. Clinical features of 46 eyes with calcified hydrogel intraocular lenses. J Cataract Refract Surg 2001;27:15961606.

4. Werner L, Apple DJ, Kaskaloglu M, Pandey S. Dense opacification of the optical component of a hydrophilic acrylic intraocular lens [commented on J Cataract Refract Surg 2001;27:1339-40]. J Cataract Refract Surg 2001;27: 1485-92.

5. $\mathrm{Yu} \mathrm{AK,} \mathrm{Ng} \mathrm{AS.} \mathrm{Complications} \mathrm{and} \mathrm{clinical} \mathrm{outcomes} \mathrm{of} \mathrm{intraocular} \mathrm{lens}$ exchange in patients with calcified hydrogel lenses. J Cataract Refract Surg 2002;28:1217-22.

6. Crema AS, Werner L, Apple DJ, Novarrete CP, Walsh A, Yamane R. Impregnação permanente por azul de tripano em uma lente intra-ocular de hidrogel. Rev Bras Oftalmol 2002;61:581-7.

7. Apple DJ, Werner L, Escobar-Gomes M, Pandey SK. Deposits on the optical surfaces of hidroview intraocular lenses. J Cataract Refract Surg 2000;26:796-7.

8. Werner L, Apple DJ, Escobar-Gomes M, Öhrström A, Crayford BB, Bianchi $\mathrm{R}$, et al. Postoperative deposition of calcium on the surfaces of a hydrogel intraocular lens. Ophthalmology 2000;107:217-85.

9. Buchen SY, Cunanan CM, Gwon A, Weinschenk JL, Gruber L, Knight PM. Assessing intraocular lens calcification in an animal model. J Cataract Refract Surg 2001;27:1473-84.

Nos artigos enviados para publicação,o nome dos autores

e suas afiliações devem estar completos. Isso facilitará a indexação e os links com as bases de dados e o CV Lates. 